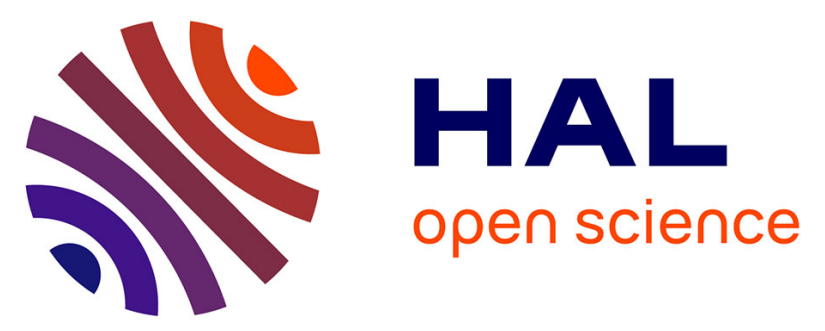

\title{
Mid-wavelength Infrared Supercontinuum Generation Spanning 1.4 Octaves in a Silicon-Germanium Waveguide
}

\author{
Milan Sinobad, Christelle Monat, Barry Luther-Davies, Pan Ma, Stephen
} Madden, David J. Moss, Arnan Mitchell, Regis Orobtchouk, Salim Boutami, Jean-Michel Hartmann, et al.

\section{To cite this version:}

Milan Sinobad, Christelle Monat, Barry Luther-Davies, Pan Ma, Stephen Madden, et al.. Midwavelength Infrared Supercontinuum Generation Spanning 1.4 Octaves in a Silicon-Germanium Waveguide. CLEO: QELS Fundamental Science 2018, May 2018, San Jose, United States. pp.FTh1E.5, 10.1364/CLEO_QELS.2018.FTh1E.5 . hal-02006480

\section{HAL Id: hal-02006480 \\ https://hal.science/hal-02006480}

Submitted on 12 Sep 2021

HAL is a multi-disciplinary open access archive for the deposit and dissemination of scientific research documents, whether they are published or not. The documents may come from teaching and research institutions in France or abroad, or from public or private research centers.
L'archive ouverte pluridisciplinaire HAL, est destinée au dépôt et à la diffusion de documents scientifiques de niveau recherche, publiés ou non, émanant des établissements d'enseignement et de recherche français ou étrangers, des laboratoires publics ou privés. 


\title{
Mid-wavelength Infrared Supercontinuum Generation Spanning 1.4 Octaves in a Silicon-Germanium Waveguide Milan Sinobad ${ }^{1,2, *}$, Christelle Monat ${ }^{1}$, Barry Luther-Davies ${ }^{3}$, Pan $\mathrm{Ma}^{3}$, Stephen Madden ${ }^{3}$, David J. Moss ${ }^{4}$, Arnan Mitchell ${ }^{2}$, Regis Orobtchouk ${ }^{1}$, Salim Boutami ${ }^{5}$, Jean-Michel Hartmann ${ }^{5}$, Jean-Marc Fedeli ${ }^{5}$, Christian Grillet ${ }^{1}$ \\ ${ }^{1 .}$ Université de Lyon, Ecole Centrale de Lyon, Institut des Nanotechnologies de Lyon (INL), UMR CNRS 5270, Ecully, France \\ 2. School of Electrical and Computer Engineering, RMIT University, Melbourne, Australia \\ 3. CUDOS, Laser Physics Centre, Australian National University, Canberra, ACT 0100, Australia \\ 4. Centre for Microphotonics, Swinburne University of Technology, Hawthorn, VIC 3122, Australia \\ 5. CEA-Leti, MINATEC Campus, 17 rue des Martyrs, 38054 Grenoble Cedex 9, France Authore-mail address: s3524959@student.rmit.edu.au
}

\begin{abstract}
We report mid-wavelength infrared supercontinuum generation, from 2.6 to $7.3 \mu \mathrm{m}$, in a CMOS compatible silicon-germanium waveguide. This 1.4 octave bright supercontinuum $(\sim 7.5 \mathrm{~mW}$ on chip generated average power) has been achieved in a low loss $(<0.4 \mathrm{~dB} / \mathrm{cm})$ dispersion engineered air-clad $\mathrm{Si}_{0.6} \mathrm{Ge}_{0.4} / \mathrm{Si}$ waveguide pumped close to the first zero-dispersion wavelength using a tunable OPA laser delivering $200 \mathrm{fs}$ pulses at $4.15 \mu \mathrm{m}$.

OCIS codes: (320.6629) Supercontinuum generation; (190.4390) Nonlinear optics, integrated optics; (140.3070) Infrared and far-infrared lasers.
\end{abstract}

In the mid-wavelength infrared band (MWIR - at $3-8 \mu \mathrm{m}$ ), most chemical and biological compounds exhibit strong and unique absorption features allowing for molecular detection applications [1]. Reliable molecular detection requires a MWIR laser source with adequate output power that is either widely tunable or yields a broadband emission to cover the whole MWIR band of interest. Supercontinuum generation in highly nonlinear waveguides is an attractive solution as it allows, in contrast to QCLs [2], for reliable molecule detection by assessing simultaneously distinct molecular absorption lines. The challenge is to achieve a supercontinuum MWIR source on a CMOS compatible chip in order to leverage the associated mature fabrication process towards mass and cheap production. To date, supercontinuum generation in the MWIR has been achieved in CMOS platforms such as $\mathrm{Si} / \mathrm{SiO}_{2}$ [3] or $\mathrm{SiGe} / \mathrm{SiO}_{2}$ [4] from 1.5 to $3.7 \mu \mathrm{m}$ and in $\mathrm{Si} / \mathrm{Al}_{2} \mathrm{O}_{3}$ [5] from 1.9 to $5.5 \mu \mathrm{m}$, but these are all intrinsically limited, on the long wavelength side, by absorption in the silica and sapphire substrate, respectively.

Here, we demonstrate the generation of 1.4 octave spanning supercontinuum in the MWIR from 2.6 to $7.3 \mu \mathrm{m}$ with a useful on-chip average power greater than $7 \mathrm{~mW}$ by pumping dispersion engineered silicon germanium waveguide $[6,7]$. Our waveguide consists of a $4.2 \mu \mathrm{m}$ thick and $4.5 \mu \mathrm{m}$ wide $\mathrm{Si}_{0.6} \mathrm{Ge}_{0.4}$ ridge with a top air cladding that seats on a silicon substrate (see inset Fig. 1b). Although the waveguide is multimode at $4.15 \mu \mathrm{m}$, the air clad design with a large SiGe cross-section (effective area of $\sim 10.5 \mu \mathrm{m}^{2}$ for both TE and TM modes) results in low anomalous dispersion (in TE and TM) across a large bandwidth (see figure 1a), a cut-off wavelength of 7.7 and $8.2 \mu \mathrm{m}$ for TE and TM polarization respectively, a strong mode confinement in the waveguide core material $(>98 \%$ at $4.15 \mu \mathrm{m})$ and a reduction of the contribution from surface roughness to the propagation loss.
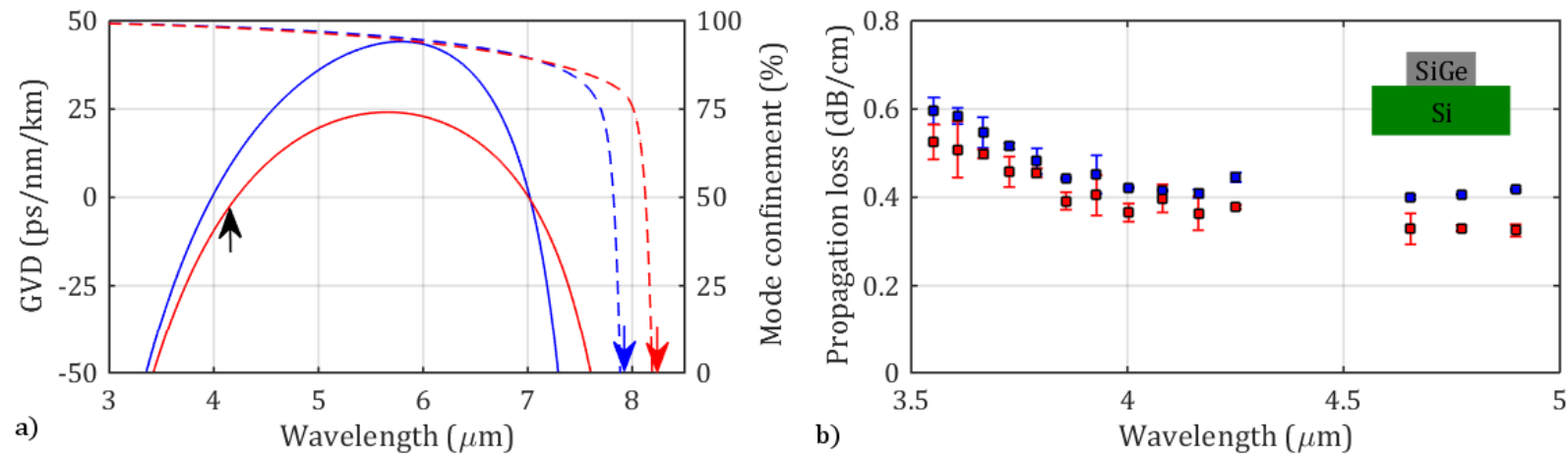

Figure 1 a) Calculated TE (blue) and TM mode (red) group velocity dispersion (GVD) and confinement of the mode field in the waveguide core (dashed lines), black arrow indicate pump wavelength, blue and red arrows indicate the cut-off wavelengths of TE and TM mode, respectively, b) Measured propagation loss for TE (blue) and TM mode (red), schematic of an air clad SiGe waveguide as an insert.

The waveguide propagation loss was first measured using a cut-back method, by probing the waveguide under relatively low average power $(<1 \mathrm{~mW})$ with $7.5 \mathrm{ps}$ pulses at $20 \mathrm{MHz}$ repetition rate. The negligible effect of the field interaction with the waveguide surface roughness at the air $/ \mathrm{SiGe}$ interface is confirmed by the low $(\sim 0.4 \mathrm{~dB} / \mathrm{cm})$ 
propagation loss measured across a wide wavelength range between $3.8-5.0 \mu \mathrm{m}$. The minimum value is $0.32 \mathrm{~dB} / \mathrm{cm}$ at $5 \mu \mathrm{m}$ for the TM mode.
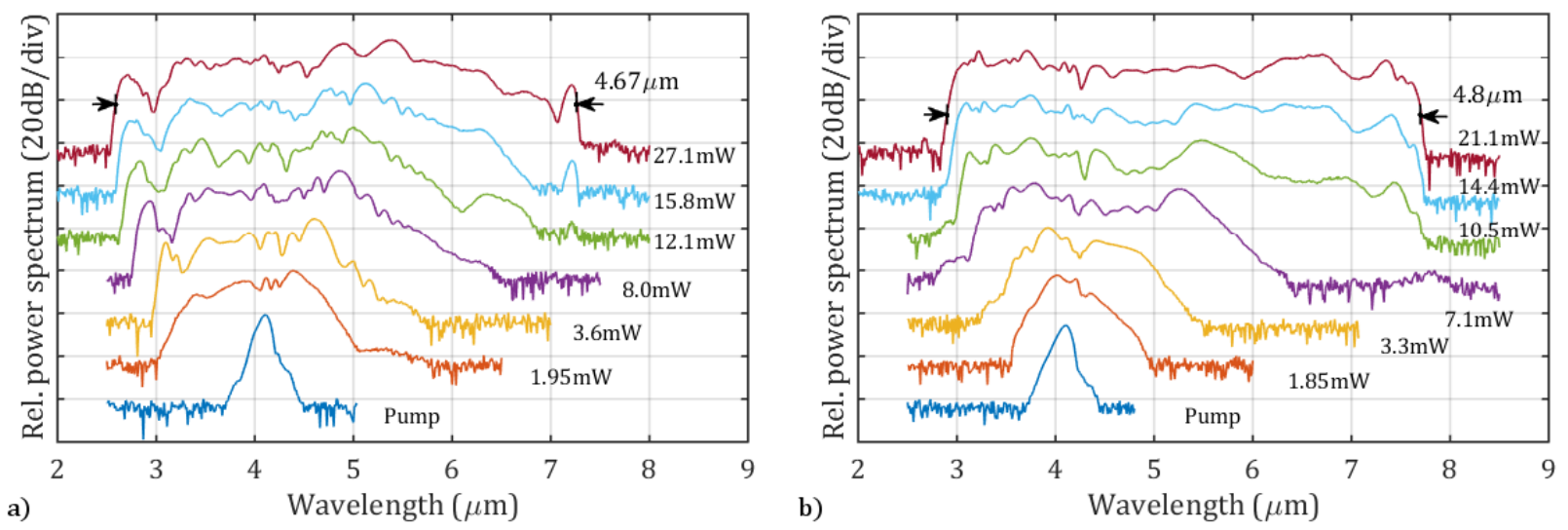

Figure 2 Output spectra measured at different average coupled power for TE mode a) and TM mode b) Coupled average power is calculated assuming $4 \mathrm{~dB}$ and $4.5 \mathrm{~dB}$ coupling loss for TE and TM mode, respectively

Supercontinuum was then achieved by pumping the waveguide with $\sim 200 \mathrm{fs}$ pulses delivered from a mid-infrared MIROPA-fs optical parametric amplifier at a repetition rate of $63 \mathrm{MHz}$. Using a $7 \mathrm{~cm}$ long waveguide pumped at $4.15 \mu \mathrm{m}$ close to the first zero-dispersion wavelength, we obtained the spectra shown in Fig 2a (TE polarization) and $2 \mathrm{~b}$ (TM polarization) for average coupled powers increasing from $\sim 1 \mathrm{~mW}$ to $30 \mathrm{~mW}$. At $27.1 \mathrm{~mW}$, we measured a supercontinuum spanning 1.4 octaves, from 2.59 to $7.26 \mu \mathrm{m}$ at $-30 \mathrm{~dB}$ level for the TE polarization. Assuming $\sim 4 \mathrm{~dB}$ coupling loss per facet, the on-chip generated supercontinuum power is $7.5 \pm 1 \mathrm{~mW}$ for $27.1 \mathrm{~mW}$ coupled average power. When pumping the TM mode, where dispersion is lower and the cut-off wavelength is slightly shifted toward longer wavelengths, a supercontinuum with a bandwidth exceeding 2.7 to $7.9 \mu \mathrm{m}$ at the $-30 \mathrm{~dB}$ level was achieved. Besides, the output spectrum measured for the TM mode is relatively smooth with a large -10dB bandwidth from 3.0 $-7.4 \mu \mathrm{m}$.

In summary, we report supercontinuum generation from a silicon germanium-on-silicon platform covering almost the whole mid-wavelength infrared, where most molecules in atmosphere have relevant fingerprints. The generated on-chip supercontinuum MWIR power and bandwidth exceed that produced so far by other Si-based platforms that are intrinsically limited by the silica or sapphire substrate absorption. This establishes silicon germanium-on-silicon as a promising platform for integrated nonlinear photonics in MWIR, with the potential to extend the operating range beyond $8 \mu \mathrm{m}$.

Acknowledgments: Agence Nationale de la Recherche (ANR) MIRSiCOMB (ANR-17-CE24-0028), H2020 EU framework, Marie Skłodowska Curie Action MSCA grant (PCIGA-2013-631543), European ERC grant GRAPHICS (648546); The Australian Research Council (ARC), Discovery Projects Program (DP150104327). We acknowledge the support of the International Associated Laboratory in Photonics between France and Australia (LIA ALPhFA), CM acknowledges the support of the Institut Universitaire de France.

\section{References}

[1] L. Zhang, A. M. Agarwal, L. C. Kimerling, and J. Michel, "Nonlinear group IV photonics based on silicon and germanium: from nearinfrared to mid-infrared," Nanophotonics, vol. 3, pp. 247-268, 2014.

[2] Y. Yao, A. J. Hoffman, and C. F. Gmachl, "Mid-infrared quantum cascade lasers," Nature Photonics, vol. 6, pp. 432-439, 2012.

[3] R. K. W. Lau, M. R. E. Lamont, A. G. Griffith, Y. Okawachi, M. Lipson, and A. L. Gaeta, "Octave-spanning mid-infrared supercontinuum generation in silicon nanowaveguides," Optics letters, vol. 39, pp. 4518-4521, 2014.

[4] M. A. Ettabib, L. Xu, A. Bogris, A. Kapsalis, M. Belal, E. Lorent, et al., "Broadband telecom to mid-infrared supercontinuum generation in a dispersion-engineered silicon germanium waveguide," Optics letters, vol. 40, pp. 4118-4121, 2015.

[5] N. Singh, D. D. Hudson, Y. Yu, C. Grillet, S. D. Jackson, A. Casas-Bedoya, et al., "Midinfrared supercontinuum generation from 2 to 6 um in a silicon nanowire," Optica, vol. 2, pp. 797-802, 2015.

[6] L. Carletti, P. Ma, Y. Yu, B. Luther-Davies, D. Hudson, C. Monat, et al., "Nonlinear optical response of low loss silicon germanium waveguides in the mid-infrared," Opt Express, vol. 23, pp. 8261-71, Apr 062015.

[7] L. Carletti, M. Sinobad, P. Ma, Y. Yu, D. Allioux, R. Orobtchouk, et al., "Mid-infrared nonlinear optical response of Si-Ge waveguides with ultra-short optical pulses," Opt Express, vol. 23, pp. 32202-14, Dec 142015. 